\title{
O fazer pedagógico e as propostas oficiais para a alfabetização em Mato Grosso do Sul: da pretensão à prática
}

\author{
The pedagogical making and the official proposals to \\ literacy in Mato Grosso do Sul: the intention and the \\ practice.
}

\section{La pratique pédagogique et le projet official pour l'alphabétisation à Mato Grosso do Sul: la prétention et l'application}

\author{
Ana Lucia ESPÍNDOLA
}

\section{RESUMO}

A alfabetização vem sendo, no decorrer das últimas décadas, objeto privilegiado de reflexão e análise. Diversas pesquisas têm sido feitas no sentido de tentar compreender este fenômeno multifacetado e, por isso mesmo, de difícil compreensão. Neste trabalho, tentamos contribuir com algumas reflexões acerca do tema estudando-o no limite da rede estadual de ensino de Mato Grosso do Sul - 1979-1982 - e no que concerne especificamente à relação entre o fazer pedagógico e as propostas oficiais postas para a alfabetização durante esse período pela Secretaria de Estado de Educação. Assim, temos como objetivo primeiramente, resgatar os projetos e propostas envolvendo a alfabetização que foram encaminhados às escolas e aos professores no período relativo a 1979-1982. Em segundo lugar, esperamos desvelar como estes projetos se efetivaram ou não no cotidiano escolar e qual relação foi estabelecida entre o fazer pedagógico da escola e os documentos oficiais. Para isso, utilizamos basicamente duas fontes para a coleta de dados: primeiramente a análise dos documentos oficiais produzidos pela Secretaria de Estado de Educação de Mato Grosso do Sul durante o período em foco. $\mathrm{O}$ resgate e análise desses documentos nos parecem ser de suma importância, tendo em vista que, mesmo sendo Mato Grosso do Sul um dos mais novos Estados da Federação, o registro de sua história educacional apresenta-se bastante comprometido, tal a dificuldade encontrada por nós para resgatar os documentos produzidos no período. Em segundo lugar fizemos uso de entrevistas semi-estruturadas com professores que fizeram parte da equipe da Secretaria de Estado de Educação na época de implantação de cada projeto. A análise desses dados nos indica haver uma grande distância entre o que foi apresentado como proposta oficial para 
a alfabetização neste período e o que se efetivou na prática pedagógica da rede.

Sul.

Palavras-chave: alfabetização, propostas, práticas, Mato Grosso do

\begin{abstract}
The literacy has being in the last decades privilege object of reflection and analysis. Several researches have being done some ways to try to understand this fenomenum with many sides and, because of this, we have immense difficult to understand it. In this work, we try to contribute with some reflections about the theme studying the situation in Mato Grosso do Sul (MS), between 1979-1982 - about the relation between the pedagogical making and official proposals. So, our aim is to rescue the projects and the proposals evolving the Literacy sent to the schools and teachers in the period related to 1979-1982. In a second moment, we expect to reveal how these projects were effective or not in the school year and what relation was establish or not in the day of the school and which relation was between the pedagogical making and the documents produced. For this, we used basically two sources to collect the datas: first the analysis of the documents made by Secretaria de Estado de Educação de Mato Grosso do Sul during the period showed. The rescue and analysis of these documents seems to be of the most importance for us, having in mind that even MS one of the newest Brazilian State of the Federation, the register of its educational history, see the difficulty find by us to rescue those documents produced during this period. In a second place, we made interviews half-structured with the teachers that were part of the Secretaria de Estado de Educação of the time the project were planted. The analysis of these datas indicates a big distance between what was presented as official proposal for Literacy in this period and what was effective in the pedagogical practice in the school web.
\end{abstract}

Index terms: literacy, proposals, practice, Mato Grosso do Sul.

\title{
RESUME
}

L'alphabétisation a été, au cours des dernières décennies, l'objet privilégié de réflexion et d'analyse. Plusieurs recherches ont été faites pour essayer de comprendre ce phénomène multiforme et, par conséquent, difficile à comprendre. Dans ce travail, nous étudions cette question au Mato Grosso do Sul (MS) - 1979-1982 - et plus particulièrement en ce qui concerne la relation entre la pratique d'enseignement et les propositions officielles pour l'alphabétisation. Ainsi, nous visons, d'abord, présenter les 
projets et propositions concernant l'alphabétisation qui ont été envoyés aux écoles et aux enseignants dans la période couvrant 1979-1982. Deuxièmement, nous espérons montrer comment ces projets sont venus passer ou non à la vie quotidienne de l'école dont la relation a été établie entre la pratique de l'école et les documents officiels. Pour cela, on utilise essentiellement deux sources de collecte de données: une première c'est l'analyse des documents officiels produits par Secrétaire de l'Éducation du Mato Grosso do Sul au cours de la période de mise au point. La récupération et l'analyse de ces documents semblent être d'une importance capitale, considérant que l'enregistrement de l'histoire de l'éducation de Mato Grosso do sul est un peu compromise, face à la difficulté que nous avons eu pour récupérer les documents produits au cours de la période. Deuxièmement, nous avons utilisé des entrevues semi-structurées avec les enseignants qui faisaient partie de l'équipe de Secretaria de l'Éducation au moment du déploiement de chaque projet. L'analyse de ces données indique qu'il y a une grande distance entre ce qui était présenté comme une proposition formelle de l'alphabétisation dans cette période et ce qui a été accompli dans les ècoles.

Mots clés: alphabétisation, les propositions, les pratiques, Mato Grosso do Sul.

\section{Introdução}

A alfabetização vem sendo, no decorrer das últimas décadas, objeto privilegiado de reflexão e análise. Diversas pesquisas têm sido feitas no sentido de tentar entender este fenômeno multifacetado e, por isso mesmo, de difícil compreensão.

Neste trabalho, tentamos contribuir com algumas reflexões acerca do tema estudando-o no limite da rede estadual de ensino de Mato Grosso do Sul (1979-1982) e no que concerne especificamente à relação entre o fazer pedagógico e as propostas oficiais postas durante esse período pela Secretaria de Estado de Educação.

Assim, temos como objetivo, primeiramente, por meio da análise dos documentos oficiais produzidos pela Secretaria de Educação durante o período em foco, resgatar os projetos e propostas que foram encaminhados 
às escolas e aos professores. Isso nos parece ser de suma importância tendo em vista que, mesmo sendo Mato Grosso do Sul um dos mais novos Estados da Federação, o registro de sua história educacional nos parece bastante comprometido, tal a dificuldade encontrada por nós para resgatar os documentos produzidos no período.

Vale ressaltar que precisamos fazer uso de materiais encontrados em arquivos pessoais de alguns professores bem como de outros encontrados em escolas da rede. Não havia, no momento em que realizamos a pesquisa, qualquer sistematização desses projetos por parte da Secretaria de Estado de Educação.

Em segundo lugar, esperamos compreender, por meio de entrevistas com membros da equipe da Secretaria de Estado de Educação à época de implantação de cada projeto, como estes se efetivaram ou não no cotidiano escolar e qual relação foi estabelecida entre o fazer pedagógico da escola e os documentos produzidos.

\section{A alfabetização em mato Grosso do Sul: das propostas às práticas}

O Estado de Mato Grosso do Sul tem como principal atividade econômica a agropecuária. Contava, na década de 70 (quando ocorreu a divisão desta federação brasileira), com uma população predominantemente rural, quadro este que sofreria profundas modificações nas décadas posteriores, conforme indicam os dados a seguir fornecidos pelo IBGE, MS:

\begin{tabular}{|r|c|r|r|}
\hline \multicolumn{1}{|c|}{ ANO } & $\mathbf{1 9 7 0}$ & \multicolumn{1}{|c|}{$\mathbf{1 9 8 0}$} & \multicolumn{1}{c|}{$\mathbf{1 9 9 1}$} \\
\hline POP. URBANA & 452.117 & 919.123 & 1.414 .447 \\
\hline POP. RURAL & 544.481 & 450.444 & 365.926 \\
\hline TOTAL & 996.598 & 1.369 .567 & 1.789 .373 \\
\hline
\end{tabular}


Mato Grosso do Sul surgiu no bojo de toda a efervescência política do final dos anos setenta, criado pela Lei Complementar $n^{\mathbf{o}} 31$, assinada pelo Presidente Ernesto Geisel, em 11 de outubro de 1977. A divisão era uma antiga luta das oligarquias sulistas do Estado. Entretanto, apesar das inúmeras reivindicações de grupos sul-mato-grossenses interessados, ela somente iria se concretizar durante a ditadura militar, mais precisamente em um momento em que a forma de governar do regime militar apresentava sinais de exaustão. Qual o significado da criação do novo Estado neste contexto?

Há pelo menos duas explicações para a separação. De um lado, temos a explicação do Governo Federal, pautando-se principalmente por uma linha técnica, apontando-a como uma estratégia mais ampla de integração nacional e de melhor redistribuição territorial. De outro, argumentos demonstrando que as causas não foram tão somente técnicas e que sérias questões políticas e econômicas orientaram a assinatura da Lei Complementar.

Os estudos para a redivisão territorial foram incorporados ao II Plano Nacional de Desenvolvimento em 1975. Em 1974, a SUDECO já havia começado a elaborar estudos para este fim (cf. ROCHA, 1992)

A necessidade de dividir o Estado de Mato Grosso era justificada pelo Governo Federal como decorrente da grande extensão territorial e das diferenças geográficas, econômicas, históricas e culturais. A justificativa oficial apontava para o fato de ser a efetivação da divisão o coroamento de um longo processo histórico de luta dos sulistas pela emancipação. Segundo Rocha (1992), porém, não se pode visualizar uma relação direta e imediata entre as reivindicações históricas de divisão do Estado e o ato que a efetivou. Para a autora, há no processo divisionista uma clara necessidade de reprodução do capital. No II PND podemos encontrar a explicação para este 
fato, pois nele é atribuído ao setor agropecuário um papel de sustentar o 'alto' dinamismo da economia, reduzir o déficit na balança de comércio, colaborar na manutenção do crescimento acelerado e abrir novas frentes na conquista de mercados externos. Para tanto, se fazia necessário, naquele momento, o pleno aproveitamento do potencial produtivo das regiões agropecuárias do país (Cf. ROCHA, 1992, p. 27).

Como as oligarquias do sul tinham uma estrutura econômica assentada basicamente na pecuária, a criação de um novo Estado forneceria condições para o aceleramento desse processo. Além disso, a criação de uma nova unidade federativa viria servir de sustentação ao regime militar. $\mathrm{O}$ novo Estado implicava a criação de mais uma bancada de três senadores e oito deputados federais, o que significava a ampliaçáo da base parlamentar da ditadura militar (Cf. FERREIRA Jr, 1992). Manter uma maioria no Congresso (dois terços) para a aprovação de suas propostas era condição imprescindível para o governo da "revolução".

Embora, conforme afirmou Rocha (1992), não existisse uma relação direta e imediata entre a divisão efetiva e as reivindicações históricas, tendo em vista que ela vinha cumprir outras funções, é inegável que, de certa forma, esses grupos foram atendidos em suas reivindicações. Assim, nasceu o Estado de Mato Grosso do Sul, criado, segundo Bittar (1992, p. 17), para "contemplar os interesses políticos da classe dominante local e para reforçar, em termos imediatos, o governo da ditadura militar".

A instalação oficial do governo se deu em $1^{\circ}$ de janeiro de 1979 , com a posse da Assembléia Legislativa, eleita em 1978, com poderes constituintes, e do governador Harry Amorim Costa, um tecnocrata indicado por Geisel, conforme assegurava a Lei Complementar $n^{\circ}$ 20/74 em uma tentativa de abrandar as divergências dentro do próprio partido situacionista, em Mato Grosso do Sul: a ARENA. 
As divergências fragmentavam a ARENA em três tendências, que lutavam para obter a hegemonia política local: a ala dos "Ortodoxos", que se mantinham fiéis aos ideais da "revolução de 64", a dos "Independentes", que se organizavam em torno do nome de Pedro Pedrossian e representavam tanto os interesses das elites agrárias como das camadas médias urbanas; e a de um grupo denominado de "Renovadores", que se constituía de dissidentes do grupo dos "Independentes".

O governo federal tinha interesse em um partido forte, em virtude das eleições que se avizinhavam para governador de Estado. Apesar de ser Pedrossian, na ótica do Governo Federal, o mais indicado para administrar o novo Estado, sua rejeição pela ala dos "Ortodoxos", que o acusava inclusive de corrupção, invibializou a sua indicação. As rusgas entre os defensores da situação em nada contribuiriam para o fortalecimento do poder central, o que levou Geisel a administrar as brigas entre os membros da ARENA com a indicação de alguém que não fosse do Estado e estaria, portanto, em posição de neutralidade em se tratando da política local.

Entretanto, a tranqüilidade sonhada pelo governo federal estava longe de se concretizar. O governo de Harry Amorim Costa viveu sucessivas crises durante seu curto período de existência, causadas principalmente por ter, tanto ele como seus assessores,

limitado o âmbito de ação dos políticos, uma vez que as decisões governamentais (...) eram tomadas sem a participação ou com a participação apenas parcial dos deputados estaduais e federais e também dos senadores (ROCHA, 1992 p. 37).

Logicamente, em um Estado com uma oligarquia com sede de poder e com forte traço clientelista, a atitude do governador e sua equipe não agradou aos políticos do Estado, tanto da situação, como da oposição. Rocha (1992) afirma que os deputados estaduais, tanto arenistas como 
emedebistas, tinham pretensão de continuar influenciando na nomeação de funcionários e na indicação de prefeitos das áreas consideradas de "segurança nacional".

No entanto, Harry mudou sua forma de governar buscando o apoio de prefeitos (até então, o único grupo que o apoiava era o grupo "renovador" liderado por Levy Dias) e aproximando-se de deputados estaduais em busca de sustentação política. Porém, mesmo alcançando seu objetivo, isso não foi suficiente para mantê-lo no poder. O governador foi exonerado pelo Presidente João Batista Figueiredo, que assumira a Presidência da República em março de 1979 e respondia às pressões dos grupos arenistas que, finalmente, tinham conseguido administrar suas diferenças e garantir a indicação de um integrante aparentemente aprovado pelos grupos "ortodoxos" e "independentes": Marcelo Miranda Soares (Cf. ROCHA, 1992).

O governo de Soares também não conseguiu agradar ao Governo Federal por muito tempo e teve duração efêmera. Um ano e quatro meses após sua nomeação, foi exonerado, em virtude das pressões de Pedrossian junto ao governo federal, tendo em vista seu desejo, já manifesto, de vir a ser o governador de Mato Grosso do Sul.

O terceiro nome indicado, conforme o esperado foi o de Pedrossian, que era considerado por Figueiredo a "maior força eleitoral do Estado" (Cf. ROCHA, 1992). Entretanto, de várias frentes surgiram manifestações contrárias a sua indicação. De um lado, Paulo Brossard, do PMDB gaúcho, retomou a tese que já havia defendido quando da indicação de Soares, questionando a legalidade do ato do Presidente, tendo em vista o fato de o Estado já se constituir como autônomo e, portanto, devendo eleger seu governador via colégio eleitoral. Por outro lado, inimigos de Pedrossian voltavam a levantar acusações sobre sua idoneidade moral, mediante graves 
denúncias de corrupção. Todavia, o nome do terceiro governador foi aprovado pelo Senado com 33 votos favoráveis e 24 contrários, vindo a tomar posse em 7 de novembro de 1980 (Cf. ROCHA, 1992).

As sucessivas indicações de governadores pelo Poder Central, quando o Estado já se encontrava política e juridicamente constituído, somente podem levar a concluir, conforme já observado, que a criação do Estado veio exatamente para viabilizar a ampliação da representação política do partido no poder. No entanto, ainda não seria desta vez que o governo teria tranqüilidade, pois a administração de Pedrossian foi marcada por atitudes autoritárias e centralizadoras, por uma política de arrocho salarial (Cf. BITTAR, 1992) e principalmente por acusações de corrupção.

No que se refere ao magistério, além do arrocho salarial imposto aos professores, a partir do final do primeiro semestre letivo de 1981o governo começou a atrasar o pagamento de salários da categoria (Cf. FERREIRA Jr, 1992), gerando, assim, a primeira tentativa de greve de professores do novo Estado.

Essas atitudes e as acusações à administração de Pedrossian levaram a um profundo desgaste de seu governo que, juntamente com a tentativa de redemocratização da sociedade, fez que "a maior força eleitoral do Estado", na visão do Governo Federal, não conseguisse eleger seu sucessor.

Uma das pretensões proclamadas pelo Palácio do Planalto, em relação à criação do Estado de Mato Grosso do Sul, era a de que seria um modelo de administração pública (Cf. ROCHA, 1992). Com base nessa aspiração foi criada uma estrutura compacta de governo com poucas Secretarias de Estado: de Planejamento e Coordenação Geral, de Fazenda e de Administração, de Desenvolvimento de Recursos Humanos, de 
Desenvolvimento Econômico, de Infra-estrutura regional e urbana, de Justiça e de Segurança Pública (Cf. ROCHA, 1992).

Para desenvolver as ações na área educacional, foi criada em janeiro de 1979, ligada à Secretaria de Desenvolvimento de Recursos Humanos SDRH - a Fundação de Educação, com a finalidade de promover, orientar, coordenar, executar e controlar as atividades direta e indiretamente ligadas aos assuntos de ensino (Cf. ROCHA, 1992).

Entretanto, esta estrutura compacta não se solidificou e assim que o primeiro governador - Harry Amorim Costa- foi substituído por Marcelo Miranda Soares, houve também a substituição das fundações por respectivas Secretarias de Estado, sendo criada a Secretaria de Estado de Educação, em outubro de 1979.

O cargo de Secretário de Educação, a exemplo e também como consequiência do que acontecia com a indicação de governadores, foi ocupado por diferentes pessoas, pois a cada novo governador indicado pelo Governo Federal, novas mudanças nas Secretarias Estaduais também aconteciam.

Essas consecutivas mudanças de Secretários e também de governadores refletem o fato de que a pretensão proclamada pelo Governo Federal de fazer de Mato Grosso do Sul um Estado modelo de administração não foi alcançada. Na verdade, o que se pode observar é que

o Estado recém-criado nada mais foi que um feudo político, onde predominou o princípio do clientelismo em detrimento das diretrizes e princípios tecnocráticos, delineados pelo próprio Planalto. Os cargos públicos, no período de 1979 a 1982, foram manipulados como oportunidades que se aproveita e explora, conforme os interesses da vida corrente pública (ROCHA, 1992, p. 59). 
Em 1978, antes, portanto, da instalação oficial do Estado que aconteceu em $1^{\circ}$ de janeiro de 1979 , foi criado o "Grupo Executivo para o Desenvolvimento de Recursos Humanos", que contava com uma equipe específica para a área educacional. Foi esta equipe que ficou responsável por elaborar a proposta das primeiras diretrizes para a educação do novo Estado, incluindo as orientações sobre alfabetização.

O documento foi elaborado inicialmente por um grupo constituído por técnicos da antiga Secretaria de Educação do Estado de Mato Grosso e membros das Delegacias de Ensino de cada região pólo, assessorados por professores da Universidade de Passo Fundo, Rio Grande do Sul. Entretanto, por questões de disputa entre os diferentes grupos partidários, as diretrizes somente seriam publicadas em 1980, no governo de Marcelo Miranda Soares, e por uma equipe diferente daquela que a elaborou.

O documento era constituído de dois volumes: no primeiro, contendo a parte de fundamentação teórica, eram apresentados aos professores os princípios que norteavam a concepção de educação proposta para o Estado de Mato Grosso do Sul. Esses princípios eram descritos sob diferentes aspectos: base legal, base filosófica, base psicossocial e base sócio-cultural. No segundo, publicado como um "Manual para operacionalização das Diretrizes Curriculares do ensino de $1^{\circ}$ grau: $1^{\circ}$ a $4^{\circ}$ série", eram apresentadas as sugestões metodológicas que deveriam ser utilizadas pelos professores, para que os princípios descritos no primeiro documento fossem atendidos.

Quanto à base legal, o documento afirmava que estava alicerçado na concepção de educação expressa na Constituição Federal bem como na Lei Federal $n^{\circ} 5692 / 71$. Esta lei é a mais clara manifestação dos preceitos do tecnicismo pedagógico e, talvez por causa disso, é possível identificar nas Diretrizes Curriculares muitas marcas desta tendência, como, por exemplo, 
a excessiva preocupação com o aspecto formal do planejamento, caracterizado em muitos momentos como a solução para todos os problemas educacionais.

Na explicitação da base filosófica do documento, podemos observar algumas contradições. Se, por um lado, buscava, muitas vezes, uma concepção libertadora de educação, citando Paulo Freire e falando no homem como "agente de mudanças", (SE-MS, 1980, p. 9) por outro, é expressa em todo o documento uma grande preocupação com o "desenvolvimento harmonioso do homem", que deverá "integrar-se" ao meio. Ora, esse "integrar-se" com "harmonia" quer-nos parecer muito mais um convite à submissão que à reflexão sugerida pela pedagogia de Paulo Freire.

O "Homem" com o qual o texto se preocupava nos parece ser um homem descontextualizado e a-histórico, pairando sobre os conflitos sociais: (...) a educação consiste em permitir, pela diversidade de oportunidades, que cada indivíduo venha a ser uma pessoa no mais lato significado que se possa conferir ao termo (SE-MS, 1980, p. 10).

O que é ser "uma pessoa no mais lato significado que se possa conferir ao termo" torna-se algo bastante difícil de ser definido.

$\mathrm{Na}$ fundamentação relativa à base biopsicossocial, já se pode observar, em alguns momentos, a exemplo da Lei 5692/71, a presença de termos buscados na teoria piagetiana.:

O indivíduo se desenvolve em dois sentidos: biológico e psicológico - intimamente relacionados e dependentes, apresentando uma caraterística comum: orientarem-se, essencialmente, para o equilíbrio (SEMS, 1980, p. 11). 
ou ainda:

Atendendo às características da criança na faixa etária de 7 a 11 anos fase das operações intelectuais concretas e dos sentimentos morais e sociais de cooperação, fundamenta-se o currículo por atividades (SE-MS, 1980, p. 11).

Fica difícil afirmar se havia já por parte dos elaboradores das Diretrizes uma preocupação em colocar alguns princípios da teoria piagetiana para se repensar o currículo, ou se a presença desses termos se explica apenas por estarem presentes na Lei 5692/71 e, nesse sentido, serem tomadas como referência para a elaboração das Diretrizes Curriculares.

Quanto à questão específica da alfabetização, a principal preocupação que marca o documento é a que diz respeito à formação de conceitos por parte do alfabetizando e ao trabalho nas séries iniciais por atividades, de acordo com as orientações contidas na Lei Federal 5692/71.

O trabalho pedagógico seria desenvolvido, nestas séries, a partir de algumas idéias principais que seriam trabalhadas no decorrer do ano letivo. Estas idéias seriam: a) O homem é um ser identificável; b) O homem sente e percebe o mundo em que vive; c) O homem tem um corpo constituído de diferentes partes e cada parte tem sua função; d) O homem é capaz de realizar movimentos; e) $\mathrm{O}$ homem não está só no mundo em que vive; f) $\mathrm{O}$ homem tem necessidade; g) $\mathrm{O}$ homem pode se comunicar através de diferentes formas; h) O homem é capaz de criar; (SE-MS, 1982 pp.17-39). Com base nessas idéias principais é que as demais atividades seriam desenvolvidas em todas as áreas, através das técnicas de "Unidade Operacional", "Centro de Interesse" e "Projetos", visando sempre ao trabalho de forma integrada. 
O documento é exaustivo no que se refere à elaboração de objetivos e comportamentos esperados para serem trabalhados em cada uma das idéias principais, reforçando nossa afirmação sobre a excessiva preocupação com os aspectos formais do planejamento. No entanto, poucas considerações teóricas são traçadas sobre o trabalho proposto, transformando o documento em apenas um receituário sem muita consistência teórica.

No que se refere especificamente à aquisição da língua escrita não são apresentadas sugestões além daquelas para serem trabalhadas no período preparatório, extremamente reforçado como fundamental para a criança lograr sucesso em sua alfabetização, além de servir como critério para o reagrupamento de classes.

Há também uma rápida descrição de cada uma das técnicas sugeridas (Unidade Operacional, Centro de Interesses e Projetos). Entretanto, a maior preocupação, novamente, recai em "ensinar" como organizar o planejamento, cada uma de suas etapas descritas detalhadamente - da elaboração de objetivos operacionalizados a avaliações - sem maiores considerações teóricas.

É possível perceber nos dois volumes do documento produzido pela Secretaria de Educação marcas de forte cunho tecnicista, o que é até certo ponto compreensível, pelo fato de ser esta a tendência predominante no cenário educacional da época.

Se, por um lado, o documento é exaustivo no que se refere aos aspectos formais do planejamento de ensino por outro, é bastante omisso no que diz respeito especificamente à aquisição da língua escrita: das 644 sugestões de atividades listadas nas situações de experiências propostas, 
menos de 40 são dedicadas a atividades específicas de aquisição desta tecnologia.

As diretrizes curriculares não recomendavam o uso de qualquer cartilha específica e seus elaboradores acreditavam que seria possível o professor elaborá-la juntamente com seus alunos, conforme palavras da professora Jan uma das técnicas participantes na elaboração da primeira versão do documento representando a cidade de Três Lagoas:

Quando nós terminamos a elaboração das diretrizes, também ficamos na dúvida: e agora, que livro, que cartilha escolher para o professor trabalhar junto às diretrizes? Não, não tem, ficou definido que não teria [cartilha], porque o professor não teria condições de trabalhar com essa ou aquela (...), ele poderia ter cartilhas ou pré-livros para consultar, mas não para adotar em sala de aula..

Acreditamos que o fato de se abrir mão da cartilha, confiando na potencialidade do professor para elaborá-la, representou um avanço para uma época em que as cartilhas eram praticamente os únicos instrumentos utilizados para a alfabetização. Entretanto, justamente por ser permitido ao professor a elaboração de seu próprio material de leitura, seria indispensável o enriquecimento de sugestões de atividades para desenvolver a língua escrita, tendo em vista a falta de experiência dos professores alfabetizadores na realização dessa tarefa, pois até então todos adotavam cartilhas para realizar seu trabalho. Pedir aos professores para que abandonem antigas práticas sem que outra opção seja apresentada é algo bastante perigoso, senão inócuo.

A introdução das diretrizes na rede não aconteceu, entretanto, da forma prevista pela equipe responsável pela sua elaboração. Por questões de recomposição política do grupo no poder, esta foi afastada da Secretaria de 
Educação e, para a divulgação do documento junto aos professores, outra equipe foi designada.

Durante esse processo, algumas mudanças foram feitas, em detrimento da concepção inicial da não adoção de cartilha. Por entender que o trabalho do professor ficaria "muito solto", se não estivesse apoiado por um manual (segundo depoimento da professora Jan), a equipe responsável pela implantação, diferentemente do que havia decidido o grupo responsável pela elaboração do trabalho, optou por adotar uma cartilha para ser utilizada por toda a Rede de escolas estaduais do antigo $1^{\circ}$ grau. A escolhida, por ser considerada mais adequada ao que estava proposto nas diretrizes, foi a cartilha elaborada por Iêda Dias da Silva- (1978, 1979)- "O barquinho Amarelo" - 'Método da experiência criadora', que trabalhava na perspectiva da abordagem analítica em alfabetização.

A adoção pela Rede Estadual de ensino de tal abordagem para a alfabetização revelou-se bastante complicada. Com uma experiência fundamentada na alfabetização pelas abordagens sintéticas, os professores da rede, em sua maioria, apresentaram imensa dificuldade para realizar o trabalho em outra perspectiva, gerando confusões e insatisfação em todas as escolas.

$\mathrm{Na}$ verdade, é possível afirmar que em poucas salas de aula o trabalho foi feito conforme o formalmente previsto (esta afirmação é confirmada por todos os técnicos que participaram da instituição da cartilha "Barquinho Amarelo" como cartilha obrigatória na rede). Segundo a professora Mar, professora à época da implantação do "Barquinho Amarelo" na Rede Estadual, na cidade de Campo Grande:

A gente foi treinado para fazer planejamento. Só. Sabe o que que todo mundo fazia? Fazia o planejamento e entregava para o supervisor, 
entrava na sala e fazia o que sabia. Voltava ao A-E-I-O-U, BA-BE-BI-BO$B U$.

O que podemos constatar na exposição da professora é que novamente a preocupação maior estava nos aspectos formais do planejamento, havendo um cuidado com o que se iria entregar à supervisão. Entretanto, o que acontecia em sala de aula nem sempre era condizente com o que constava no plano. Essa idéia é corroborada pelas palavras da professora Ter, na época supervisora de duas escolas estaduais na cidade de Três Lagoas:

Havia um desespero dos pais, havia um desespero no professor; o professor não tinha consciência de esperar [para destacar as sílabas]. Tinha professor que fazia escondido da gente [supervisão]. Ele destacava na primeira lição, já demarcava a palavra chave.

Há uma unanimidade entre os técnicos entrevistados para a realização dessa pesquisa que participaram da tentativa de utilização da proposta: ela não se efetivou na prática. Por que isso aconteceu?

Podemos observar que, se por um lado, o professor resistiu à implantação da proposta, talvez até pelo desconhecimento que tinha em relação ao que estava sendo proposto; por outro, com certeza houve falha na forma de conduzir essa tentativa de implantação.

O curso de treinamento oferecido pela Secretaria de Educação, ministrado pela própria autora da cartilha, Iêda Dias da Silva, era dado apenas aos supervisores da rede que se encarregavam de se tornar multiplicadores. 
É evidente que essa prática dificultava em muito o próprio processo de convencimento e compreensão da proposta por parte do professor alfabetizador, que preferia continuar com aquilo que, de uma forma ou de outra, dominava e sentia-se seguro a aventurar-se em uma proposta nova e completamente estranha à sua prática até então.

Outro aspecto a se considerar é que a mudança na metodologia veio de forma verticalizada (o que, aliás, é prática bastante comum, e é muito mais regra que exceção, não só em Mato Grosso do Sul), instituída pela Secretaria de Educação, sem que houvesse uma real inquietação dos professores com o método que utilizavam até então para alfabetizar. Assim, a mudança na metodologia, determinada inicialmente por meio das diretrizes e, posteriormente, com a indicação da cartilha, respondia a uma necessidade da Secretaria de Educação e não propriamente dos professores atuantes em sala de aula.

O depoimento da professora Ter corrobora com nossas afirmações quando afirma que os professores destacavam as sílabas" antes do previsto $e$ às escondidas da supervisão escolar, além de comprovar nossa afirmação, mostra o nível de democratização que havia na prática escolar.

Entretanto, em que exatamente se diferenciava a abordagem analítica, utilizada no Barquinho Amarelo, das abordagens sintéticas, propostas pelas outras cartilhas? $\mathrm{Na}$ verdade, tanto para uma, como para outra abordagem a escrita é apenas um código de transcrição que converte os sons em grafia e não um sistema de representação que precisa ser compreendido. Por isso é dada tanta importância às discriminações visuais e auditivas que têm prioridade no chamado "período de prontidão".

A escrita é tratada no manual do pré-livro "Barquinho Amarelo" como "traçado das letras", e como algo que "começa com a cópia" (SILVA, 
1978, p.47), dependendo, portanto, "do amadurecimento dos músculos do braço, mão e dedos" (SILVA, 1978, p.44). Em momento algum se fala na aprendizagem da escrita como algo que envolve outros mecanismos além dos motores.

Não é objetivo deste trabalho avaliar os problemas apresentados pelas cartilhas, já denunciados reiteradas vezes. Entretanto acreditamos que o "Barquinho Amarelo" não consegue ficar isento às críticas mais comuns feitas à maioria delas: textos desinteressantes e sem significado, preocupados apenas em evidenciar certas estruturas da língua, conforme afirma Bettelheim (1984) que, embora estejam se referindo às cartilhas americanas, permitem-nos estender a crítica também às cartilhas brasileiras e particularmente ao "Barquinho Amarelo":

(...) a simplicidade das proposições não encoraja o investimento da energia mental na leitura nem permite a transmissão de qualquer coisa interessante. A dicção usada é literalmente a da conversa de bebês, parecida com a fala 'telegráfica' truncada das crianças que estão aprendendo a andar; entretanto, a criança devia ser levada a sentir que aprender a ler á algo progressivo e não algo que a leva a regredir a maneira de pensar e falar que ela já superou muito bem (BETTELHEIM, 1984, p.174).

Conforme já afirmamos, a cartilha "O Barquinho Amarelo" não chegou a ser usada efetivamente na maioria das escolas. Entretanto, em 1982, os professores de várias cidades foram atendidos em um abaixoassinado dirigido à Secretaria de Educação, pedindo o fim da execução das diretrizes, bem como da utilização obrigatória da cartilha "Barquinho Amarelo" nas escolas. Assim, chegou ao fim, formalmente, a tentativa de utilização da abordagem analítica para a alfabetização na rede estadual do Estado de Mato Grosso do Sul. 
No final do governo de Pedro Pedrossian, "por uma decisão a nível de [sic] secretário", professor Fauze Scaff Gatass Filho (segundo depoimento de Jôn), foi desenvolvido um segundo projeto, o Alfa, que foi comercializado pela Editora Abril. Entretanto, talvez pelo custo altíssimo que representava, sua utilização não seguiu os moldes do "Barquinho Amarelo" e apenas algumas salas de aula da rede Estadual foram escolhidas para utilizá-lo.

Igualmente à cartilha "O Barquinho Amarelo", o "Programa Alfa" foi extinto sem que houvesse uma avaliação mais precisa de seus resultados. O Projeto foi abandonado por falta de verbas (segundo depoimento da professora Jôn) e alguns anos após o início de sua utilização, era possível encontrar nas escolas restos abandonados do material utilizado pelo projeto.

O que podemos concluir em relação à utilização do Alfa é que, apesar de ter sido um projeto de custo extremamente elevado ao poder público, o acompanhamento de sua efetivação foi irresponsável, não havendo qualquer avaliação dos resultados obtidos.

\section{Considerações finais}

Analisando as circunstâncias da tentativa de utilização das diretrizes curriculares, bem como da cartilha "Barquinho Amarelo" e do "Projeto Alfa", observamos que houve um profundo descompasso entre as propostas contidas nos documentos oficiais e a prática pedagógica efetivada na rede. Diferentes razões podem ser apontadas para isso. A primeira delas é a de que a conjuntura autoritária das administrações estaduais nomeadas pelo governo da ditadura militar é refletida na forma como as questões da prática escolar são encaminhadas. Decisões centralizadas, impostas de cima para baixo, sem a devida participação da comunidade escolar, caracterizaram o trato dispensado às questões do ensino nesse período. 
Assim, as propostas apresentadas pela Secretaria de Educação para a alfabetização não respondiam a angústias e questões colocadas pelos professores e, portanto, estes não se sentiam convencidos de sua necessidade ou validade. Outra questão que, embora não tenha sido objeto de estudo dessa pesquisa, não pode ser desprezada é a formação dos professores alfabetizadores para lidar com essas novas orientações propostas, pois não nos parece possível desvincular estes professores das condições concretas de vida e trabalho a que estavam submetidos.

Por fim, acreditamos que o não acolhimento por parte dos professores a estas propostas pode ser entendida também como uma forma de resistência velada aos encaminhamentos feitos pela Secretaria de educação, dada a conjuntura autoritária em que foram gestados.

A escola, embora inegavelmente atravessada pelas contradições sociais colocadas por um determinado momento histórico, pode também ser palco de resistência e da criação do novo.

Dessa forma, entre a pretensão dos documentos oficiais e a prática pedagógica efetiva no cotidiano escolar nos perguntamos se o que fica é apenas o vazio ou se o que se apresenta é a necessidade do professor de resistir para assim se fazer sujeito da história, direito que lhe tem sido sistematicamente negado durante décadas.

\section{Referências bibliográficas}

BITTAR, Marisa. Estado e política educacional em MS (1983-1986): limites de uma proposta democrática. 1992. 148 f. Dissertação (Mestrado) Centro de Ciências Humanas e Sociais da Universidade Federal de Mato Grosso do Sul, Campo Grande, Mato Grosso do Sul, 1992.

BETTELHEIM, Bruno (1984). Psicanálise da alfabetização: um estudo psicanalítico do ato de ler e aprender. Porto Alegre: Artes Médicas. 
FERREIRA Jr. Amarílio. A FEPROSUL e a luta sindical dos professores estaduais de $1^{\circ}$ e $2^{\circ}$ graus: 1979-1986. 1992. 130 f. Dissertação (Mestrado) Centro de Ciências Humanas e Sociais da Universidade Federal de Mato Grosso do Sul, Campo Grande, Mato Grosso do Sul, 1992.

RAZZINI, Márcia de Paula Gregório. A livraria Francisco Alves e a expansão da escola pública em São Paulo. In: I SEMINÁRIO BRASILEIRO SOBRE O LIVRO E HISTÓRIA EDITORIAL. Rio de Janeiro, p. 1-20, 2004.

ROCHA, Doroti. A gestão da educação pública em MS: práticas racionalizadoras e clientelismo. 1992. $151 \mathrm{f}$. Tese (Doutorado) - Faculdade de Educação da Pontifícia Universidade Católica de São Paulo, São Paulo, SP, 1992.

SECRETARIA DE ESTADO DE EDUCAÇÃO/MS (1980). Diretrizes Curriculares - Ensino de $1^{\mathrm{o}}$ grau - $1^{\mathrm{a}}$ à $4^{\mathrm{a}}$ série, Mato Grosso do Sul, 1980.

(1980). Manual

para operacionalização das Diretrizes Curriculares do ensino de $1^{\circ}$ grau - $1^{\mathrm{a}}$ a $4^{\mathrm{a}}$ série, Campo Grande, 1980.

SILVA, Ieda Dias da. (1978). Método de experiências criadoras: manual do Pré-Livro "O Barquinho Amarelo". Belo Horizonte: Vigília.

Belo Horizonte: Vigília.

(1979). O Barquinho Amarelo - Pré-Livro (1979).

VALDEMARIM, Vera Teresa (2000). Lições de coisas: concepção política e projeto modernizador para a sociedade. In: Cadernos Cedes, Campinas, ano XX, nº 52, p. 74-87, novembro. 


\section{Autora:}

Ana Lucia Espíndola

Professora Doutora do Departamento de Educação da Universidade Federal de Mato Grosso do Sul - Campus de Três Lagoas.

Contato: anaespindola@uol.com.br

\section{Como citar este artigo:}

ESPÍNDOLA, Ana Lucia. O fazer pedagógico e as propostas oficiais para a alfabetização em Mato Grosso do Sul: da pretensão à prática. Revista ACOALFAplp: Acolhendo a Alfabetização nos Países de Língua portuguesa, São Paulo, ano 5, n. 9, 2010/ 2011. Disponível em: <http://www.acoalfaplp.net>. Publicado em: setembro de 2010 - março de 2011.

Recebido em março de 2009./ Aprovado em dezembro de 2009. 